undergo amputation. 2. A girl, aged fourteen, had most extensive sinuses leading to bare bone. She refused to submit to amputation, left after four months in the infirmary, and has since died. 3. A girl, aged twelve, after sixteen months' residence with exposed bone, discharge, and incomplete union, is improving, with a fair prospect of the limb being saved. 4. A lad, aged thirteen, came down, ten months after operation, with bare bone, numerous sinuses, and exhausting discharge. The limb was amputated. 5. A lad, aged thirteen, admitted with the limb in very bad position, numerous sinuses, and bare bone. He was removed after two months, and the result is unknown. Two children, of the age of seven, had limbs firmly united, though one was not in good position; and a boy, aged eleven, had a limb imperfectly united, and exposed bone at the upper part of the tibia." We must be cautious, however, in drawing conclusions unfavourable to excision of the knee from this report; for we are unable to put against the unsuccessful cases those in our hospitals in which, during the same period, the operation has preserved a useful limb, and promoted restoration to health.

Apparatus of various kinds has been used for securing the limb in good position after the operation. I have found none more convenient or efficient than the interrupted plaster-of-Paris casing, which has been employed in cases of this operation by my colleagues, Messrs. Maunder and Little. The casing seems to combine all the objects desired-firm and continuous support to the limb without undue pressure, and space leaving the wound free for dressings, applications, and the escape of discharges, \&c. If the limb swells, and the casing becomes too tight, it can be divided longitudinally, without disturbing the parts or weakening the support.

CLINICAL OBSERVATIONS oN

\section{LESIONS OF ARTERIES AND SOME EFFECTS OF THE DELIGATION OF THEIR TRUNKS.}

Bx JOHN D. HILL, F.R.C.S.,

SURGEON TO THE ROYAL FREE HOSPITAL, AYD ASSISTANT-SURGEON TO THE ROYAL OBTHOPADIC HOSPITAL.

Accidents and injuries to the human body often provide us with opportunities for observation and research which otherwise would perchance seldom occur. By such opportunities we become familiar with the variations in the natural process of repair in structures generally, and are safely guided to the exact period when nature indicates the resources of surgical art. Now of the various structures affected by injury or disease during my hospital career, lesions of arteries have afforded me facilities for remarking some effects of ligaturing their supplying trunks. My attention was first directed to this subject by several concurrent results following operations which were rendered imperative by reason of copious secondary hæmorrhage. In these cases the affected extremities were respectively in a state of inflammation, erysipelas, and phagedena; and it will be observed that in every instance the operation was followed by a twofold issue-namely, (1) the control of hæmorrhage, and (2) the arrest of a morbid process in the extremity. These circumstances were briefly alluded to during a discussion upon Mr. Maunder's paper on Ligature of the Femoral Artery for acute traumatic inflammation of the knee-joint; but the particulars of each case may be of sufficient importance to merit further notice; therefore, by the courtesy of my colleagues, I am permitted to refer to some points connected with that surgical assistance which I was called upon to render.

The first case was one of "acute inflammation of the hand, after an incised wound involving both palmar arches, in which secondary hæmorrhage on the twelfth day necessitated ligature of radial and nlnar arteries."

The patient, John B-, aged fifteen years, a bricklayer's boy, of healthy antecedents, was admitted into the Royal Free Hospital, under the care of Mr. Wakley, on the 2nd Mar, 1860. Eleven dars previously, whilst whittling with a pocket-knife, he accidentally wounded his left palm, when profuse bleeding ensued. This was controlled by the pressure of a pad and handkerchief, but it recurred on the fourth, seventh, and tenth days, and the friends, having become alarmed, brought him to the hospital. When admitted, bleeding had ceased, and he was suffering from an acutely inflamed incised wound of the left palm, about one inch long, oblique in direction, and parallel to the metacarpal bone of the middle finger from base to centre. The palmar integument was dense, horny, and unyielding; and the subjacent and contiguous tissues as high as the wrist were invaded by the inflammation, which also extended along the absorbent vessels to the axillary glands. Moreover he was very feverish and out of health generally. A purgative having been administered, he was ordered a milk diet, and poppy fomentations to the affected part, which was elevated at an angle of 45 degrees.

At six o'clock on the following morning (May 3rd) the night-nurse summoned me to his bedside. I found him very faint, and bleeding from the wound, the dressings and bedelothes being saturated. The hand was tense, shing, and much swollen, and he complained of a sense of tightness in the limb, and extensive tenderness in the course of the bloodvessels, so that pressure could not be borne on the brachial, radial, or nlnar arteries. Chloroform was therefore administered, and pressure on both radial and ulnar arteries was found to control the hæmorrhage, but on compressing each vessel singly bleeding was only lessened. Under these circumstances, I cut down and ligatured first the radial and then the ulnar artery. Both vessels were large, the radial being equal to the size of a No. 7, and the ulnar of a No. 6 eatheter. -9 P.M.: Is now free from pain, and has slept ever since the operation.

May 4th.-All signs of inflammation have disappeared, and excepting the corrugation of the skin arising from the cessation of the inflammatory tension, the hand is reduced to its normal size. The palmar wound is suppurating.

15th (eleventh day after operation). - Ulnar ligature separated to-day.

16th.-Radial ligature came away this morning; incised wounds have healed in great part by first intention; palmax wound is cicatrised.

20th.-All the wounds are now healed, and beyond a little stiffness he has good use of the hand. Discharged.

The next case is similar to the preceding, and may thus be described: "Acute inflammation of the hand following a lacerated wound of the thumb, implicating the deep palmar arch ; secondary hæmorrhage on the ninth day; ligature of radial artery."

The patient, Charles $\mathrm{B}-$ - an attenuated man, thirtythree years of age, by occupation a tobacconist, and of very intemperate habits; was admitted into the hospital under the care of Mr. Wakley, on the 16th of April, 1862. Nine days previous to admission he received a wound of the left thumb through the bursting of a soda-water bottle. Profuse bleeding followed, and being near St. George's Hospital he was taken there, and treated by the house-surgeon, who arrested hæmorrhage by pressure.

For some days afterwards he went about his business, although the hand was exceedingly painful. At last another attack of hæmorrhage hastily brought him to the Royal Free Hospital at twelve P.M. He was then very faint, and bleeding from a lacerated wound in the ball of the left thumb, which coursed obliquely towards the base of the metarcarpal bone of the index finger, about two-thirds of a inch in extent, and implicating the deep palmar arch. The palmar integument was dense and horny, and the hand deep red, shiny, swollen, very painful, and of increased temperature, inflammation extending along the absorbents to the axilla. On applying pressure to the brachial or radial artery pain was produced, but compression of the latter vessel arrested all hæmorrhage; therefore I cut down and ligatured it at once. As in the first case, the artery was large, being quite equal to the size of a No. 7 catheter.

April 17th.-Ten A.M.: Is now free from pain, and the swelling of the hand is considerably reduced; slept well during the night.

18th.-Inflammation has subsided, and no swelling remains beyond the corrugation of skin; palmar wound is suppurating, and incised wound has healed in great part by adhesion. 
24th.-Palmar wound is now healed; ligature separated to-day (eighth day).

26th.-Incised wound is sound. Discharged.

A few words now as to the nature and treatment of these wounds implicating the palmar arches. In the first place, the palmar integument, in the case of labourers and artisans, is usually so dense and hypertrophied that the depth of the wound is thereby considerably increased. Next comes the palmar fascia, which, in my experience, is seldom opened in a direct line with the integument, and may be so split that its edges are not displaced; hence these conditions render ligature of the retracted vessel a matter of impossibility without enlarging the wound; and for the same reason graduated local pressure, which in other parts of the body can be successfully employed, is here often useless. Therefore I am inciined to think, both for the safety and comfort of the patient, that it is a wiser proceeding not to delay when ordinire means fail, but to ligature the supplying vessel, rather than search for the palmar branch by enlarging the wound-a course fraught with some danger to the faseia, $t \in n d o n s$, and their relations; and, on the other hand, the application of local pressure sufficient to arrest hæmorrhage may endanger the vitality of the tissues, or, if insufficient, permit subfascial bleeding. Again, where hæmorrhage recurs after the approach of inflammation (as in the foregoing cases), deligation seems to be the safest and best surrery. The large size of the arteries of the wrist would appea: to be a necessary consequence of an increased blood-supply to the extremity. This circumstance I have observed on former occasions, both in man and in the lower aninals.

The third case, although differing in the type of inflammation from the preceding ones, may be classed with them, and thus described: "Phlegmonous erysipelas of left arm, following a lacerated wound of inner aspect of elbow; secondary hwmorrhage on the ninth day; ligature of the brachial artery."

Charles G- aged twenty-three, potman, was admitted into the hospital under the care of Mr. Weeden Cooke on Nov. 17th, 1864, at 2 A.m. In a state of intoxication he fell down some steps upon the tip of an iron pallisade, which penetrated his left arm; shortly afterwards he was found by a policeman, who, seeing him in a helpless condition and bleeding, brought him to the hospital.

When first seen he was quite blanched, and bleeding had ceased. After removing a large clot of blood, a lacerated wound three inches in extent was found just below the internal condyle of the humerus; this extended through the flexor muscles, ulnar artery, and venæ comites, close to the brachial bifurcation, and exposed a small portion of the zadius below its tubercle.

Having ligatured both ends of the wounded vessels I placed the arm upon a rectangular splint and closed the pround, and he was placed on a milk diet. By the third day a good deal of reactionary fever had set in, and he complained of tenderness in the arm, which now began to take on an erysipelatous character. Ordered a good purgative of calomel and colocynth, hot fomentations locally, and an opiate at night.

By the sixth day the arm was tense, brawny, deep red, and much swollen, and, the swelling having extended to the upper arm, it was necessary to remove the splint.

was now ordered bark and ammonia, strong beef-tea, eggs, and ten ounces of brandy daily.

Eighth day.- Several abscesses in the areolar tissue were opened torday, with great relief.

Ninth day (Nov, 26th).-A bout 2 o'clock this morning secondary hæmorrhage occurred; and by the time I reached the ward, which was scarcely two minutes afterwards, bleeding had ceased, and he was completely blanched and pulseless. The arm was enormougly swollen as far as the insertion of the pectoralis major, and blood had evidently infiltrated the tissues about the wound to such an extent that to enlarge it and seek for the bleeding ressel was quite out of the question.

Having administered some brandy, return of animation tas soon manifest by a recurrence of hæmorrhage. I now compressed the brachial artery, which commanded all bleeding; but, from the inflamed state of the arm, this caused great pain. Therefore I cut down, and ligatured the vessel in the middle third of its conrse. This was remarkably large, as in the previous cases, and very deeply situated.
Nine hours after the operation inflammation had lessened, and he had slept during the interim.

Nov. 28th.-The arm is not larger than natural.

29th.- Ulnar ligature has separated (twelfth day aften the accident). Both the wounds are suppurating.

Dec. 8th (twelfth day after the operation).-Brachial ligature came away this morning. The wounds are bealing; and the patient is much improved in health.

12th.-Wounds are now healed; action of flexors is somewhat interfered with. To attend as an out-patiert, and is recommended to use the arm gradually.

Feb. 1st, 1865. - Can now fairly move the flexor"muscles; but cannot completely extend the arm because of the deep cicatricial attachment.

The fourth case, although differing in its pathological characters from those which have been described, resembles them in a surgical point of view :- "Serpiginous phagedena of stump after amputation of forearm; secondary hæmorrhage ; ligature of brachial artery."

James S - , aged thirty-seven, labourer, was admitted into the Royal Free Hospital on October 17th, 1864, under the care of Mr. de Méric. In crossing the street he was knocked down, and the wheel of a van passed over his right hand, splitting it up from the commissure of the middle and ring fingers to the articular facets of the semilunar bone. Forty-eight hours after the accident acute gangreme ensued, necessitating amputation of the forearm in its upper third. The stump progressed tolerably during the first fortnight after operation, but subsequently a serpiginous form of phagedena, attended with pain, heat, and redness of surrounding tissues, set in; this failing to succumb to any kind of local or constitutional treatment, change of air was advised, and he was made an out-patient on Dec. 3rd.

7th.-At 6 A.m. he was attacked with secondary hæmorrhage, and immediately brought back to the hospital. Phagedena had extended, and arterial blood was flowing from an ulcer about three inches square. This was, however, controlled by graduated pressure.

26th.-To this time his progress had been unsatisfactory, and at 9 o'clock this evening hæmorrhage again recurred. Direct pressure and other means failing, I compressed the brachial in its middle third. As this controlled all bleeding, I cut down and ligatured the vessel. On tightening the ligature, the artery became partly severed; I therefore locked a pair of bull-dog forceps above and below the ligature, and then cut the vessel through. Previous to ligaturing the distal and proximal ends, precaution was taken to unravel several pieces of silk thread, in order to make a broadish band to encircle the vessel, and so obviate further danger of wounding its external coat. The arterial walls were found thickened, and speckled with a yellowish-white deposit, which to the naked eye appeared to infiltrate the middle coats chiefly, but under the microscope seemed to fuse itself into the whole arterial structure. This had all the characteristics of fat. The external had evidently become so incorporated with the middle and internal coats during these morbid changes, that its strength and resistance were lost; indeed, this had been attested by the brittle and inelastic state of the vessel, the increase of its calibre, and the slight amount of retraction after severance.

27 th. $-\mathrm{He}$ is very comfortable, and there is no further sign of hæmorrhage.

29 th.-Phagedena is now arrested, and the ulcer is inclined to heal.

Jan. 1st, 1865.- Healthy granulations have sprung up, and a fine blue film of skin surrounds the margins of the ulcer.

7th.-The ligature separated this morning, and the ulcer is no larger than a threepenny-piece; wound is granulating. 16th.-Ulcer is cicatrised.

26th.-Wound (incision) is healed.

31st.-During the last few days patient has complained of rheumatic pains in the large joints.

Feb. 1st.-Discharged in good health.

In this case arterial disease probably predisposed the patient to gangrene of the extremity, and also to those molecular changes which subsequently developed in the stump. It rould seem paradoxical that increased vascularity and molecular disintegration should co-exist in contiguous structures, unless regarded as transitional steps in a morbid process - that is to say, first, in a disturbed or altered arterial circulation; second, in an embarrassed capillary and 
venous circulation; and, third, in a reactionary circulation, or loss of textural vitality: and some of these changes probably occur when a main vessel has been ligatured. Hæmorrhage may have been due to accidental rupture of a diseased arterial branch; and as to the effect upon the phagedena of ligaturing the main vessel, it may be explained by the reduction of arterial tension. Thus hæmorrhage was controlled, congestion arrested, and the equilibrium of the circulation restored; but it is not improbable that the large arterial trunks were dilated, and thus, the anastomotic circulation becoming quickly established, deligation of the main vessel was sufficient to control hæmorrhage without endangering the extremity by too sudden or complete an arrest of the blood current.

The fifth case to which I call attention may be thus described: "Erysipelatous inflammation of a stump after amputation of forearm; secondary hæmorrhage on the eighth day; ligature of brachial artery."

W. C-, aged twenty-four, gasfitter in the service of the Metropolitan Railway Company, of bealthy constitution, was admitted into the hospital, under the care of Mr. Gant, on the 18th of August, 1868. Whilst crossing the line he was knocked down by a passing train, and in attempting to save himself his right forearm caught between the wheel and metals, and was severed just above the wrist-joint. Mr. Gant performed primary amputation in the upper third of the forearm shortly after the accident. From the first his progress was unsatisfactory. Hæmorrhage occurred five hours after the operation, but was arrested by pressure. This was followed by erysipelatous inflammation of the stump, and a recurrence of bleeding, which (on the eighth day) became so excessive that, in Mr. Gant's absence, Mr. Murphy, the house-surgeon, summoned me. I found the patient very faint, and, although the tourniquet had been applied to the brachial artery as soon as possible, he had evidently lost a considerable quantity of blood. The limb was swollen and inflamed, and the stump was tense, brawny, and infiltrated with extravasated blood; this had separated the flaps, so that I easily opened up the stump, removed the coagula, and sought for the bleeding vessel. But the latter had retracted beyond view; therefore, without exploring the inflamed tissues further, I cut down and ligatured the brachial artery at the junction of its middle and lower third.

Aug. 27th.-Has passed a comfortable night, and inflammation has subsided.

29th.-Is free from pain; stump has commenced granulating.

Sept. 7th.-The ligature separated this morning (twelfth day after operation).

14th. -The wounds are hearing by granulation.

28th.-Two or three small spicula of bone have exfoliated, probably the result of inflammatory action having extended to the periosteum.

Oct. 7 th. - He is now in good health, and the wounds are quite healed. Discharged with a good stump.

The preceding and the third case are very analogous, and forcibly illustrate the points in question. I cannot help thinking that the early and repeated attacks of hæmorrhage must have been due to laceration of one or more vessels above the line of amputation. Such remote arterial injury is occasionally met with when the limb has been torn off between the wheel and flange of a locomotive.

(To be continucū.)

\section{A REMARKABLE CASE}

of

\section{CONPLETE LOSS OF HAIR ALL OVER THE HEAD AND BODY FROM CEREBRAL INJURY.}

BY R. COOPER TODD, EsQ., STAFE-SURGEOX.

the summer of 1863 , I was called to see a gentleman, aged about forty-five, at an hotel at Bray, Ireland, who had been thrown from the side of an Irish car upon his head, and received a partial concussion of the brain. Imme- diately after the accident he was quite master of himself, nd able to continue his journey, until he reached the hotel, which was about four miles from the site of the accident. When I saw him, he was slightly confused in mind, but perfectly able to answer questions, and conscious of the passing events. By my adrice he remained that night in the hotel, but the next morning, before I had time to visit him, he had left the hotel, and returned to his home in Dublin, a distance of quite twelve miles, which he accomplished by rail and by cabs. In the course of the following day, and for a few days after, some alarming symptoms supervened. Hemiplegic convulsions of an epileptiform character came on, accompanied by total unconsciousness; but the fits were of short duration, and in the interim the patient was collected. There was, however, present at times a peculiar kind of delirium, like that common in some low fevers. The patieat rose from bed, seemed anxious to hide away and lock up in his chest of drawers trifling articles, such as a grape or two, and on one occasion he tried hard to throw himself ont of his window; but at the same time, when addressed, he was quite amenable to government, and recognised those about him. In a short time he quite recovered, and in less than six weeks after the accident managed successfully some very important private business. However, in the course of time, he suffered from occasional headaches, and sought medical advice, I think, in Scotland. He underwent a course of mercury, and subsequently took daily, for about twelve months, thirty grains of bromide of potassium, when he found that one morning, on proceeding to shave, he had no beard to cut; and subsequently all his hair fell off, not only from his bead and face, but from his chest and body,-and up to this time he had been always a very hirsute man.

This peculiar result of the accident was brought to my notice only the other day by the gentleman himself. At first I was disposed to regard the depilation as the consequence of the long-continued use of the bromide of potassium. However, my friend Dr. H. Massy, staff assistantsurgeon, pointed out to me the record of a case alluded to by $\mathrm{Mr}$. Holmes in his System of Surgery, vol. i., article Accidents from Lightning, which, as far as the depilation goes, was identical with the case I record. Both cases were injuries of the head. In the latter instance the falling off of the hair began the day after the accident, but in my case about twelve months intervened. In the accident from lightning, also, the toe-uails fell off eventually, which has not yet happened to my friend, who up to the present is in capital health, although quite denuded of every hair upon him. In the former case no blame can be attached to the bromide of potassium, because it was not administered or even known, and consequently it is equally likely that in my case the falling off of the hair was solely due to the cerebral injury, and in no way to the treatment. Netley, July 5th, 1969.

ON A

CASE OF CONGENITAL ABSENCE OF THE MEATUS EXTERNUS OF THE RIGHT EAR.

BY W. S. J. H. IIUNRO, M.D., M.R.C.S. ToNd.

ON Aprii 27th, 1869, I was called to attend on Mrs. GDunkerton, who, after a few hours' natural labour, was delivered of a fine, full-grown, healthy girl. I had no reason. to suspect any deformity, and so matural did the parts appear that an experienced monthly nurse, who daily washed the child for about five weeks, detected nothing abnormal.

June 10th.-I was called in to-day, and find all the external parts normal, but no trace whatever of an external meatus to the right ear, or even a depression in the skin where it ought to be. The parents are very anxious, and I believe have shown the child to a number of my professiona] brethren in Bath; but as no case of this kind has appeared in my practice, nor can I see any on record, I now send it for publication.

Rads:otk, near Bath, June, 1899.

THE mortality from scarlet fever in London hai been steadily increasing during the last four weeks. 